\title{
Effect of acute environmental hypoxia on protein metabolism in human skeletal muscle
}

\author{
G. D'Hulst,' C. Jamart, ${ }^{2}$ R. Van Thienen,' P. Hespel,' M. Francaux ${ }^{2}$ and L. Deldicque' \\ I Department of Kinesiology, Exercise Physiology Research Group, FaBeR, KU Leuven, Leuven, Belgium \\ 2 Institute of Neuroscience, Université catholique de Louvain, Louvain-la-Neuve, Belgium
}

Received 9 November 2012, revision requested 30 December 2012

accepted 14 February 2013 Correspondence: L. Deldicque, Exercise Physiology Research Group, FaBeR-KU Leuven,

Tervuursevest I0I, 300I Leuven, Belgium. E-mail: louise.deldicque@ faber.kuleuven.be

Physiological relevance: Hypoxiainduced muscle wasting has been observed in several environmental (such as altitude) and pathological (such as lung diseases) conditions. However, the molecular mechanisms behind this loss of muscle mass are far from elucidated, certainly in vivo. To the best of our knowledge, no study has previously reported the effect of hypoxia on protein degradation in human skeletal muscle, and protein synthesis has only been scarcely studied at a molecular level. The present article reports new mechanistic explanations about the regulation of muscle protein metabolism, which is not only important for hikers who lose muscle mass during ascent but also for patients suffering from lung diseases or anaemia who present reduced muscle mass.

\begin{abstract}
Hypoxia-induced muscle wasting has been observed in several environmental and pathological conditions. However, the molecular mechanisms behind this loss of muscle mass are far from being completely elucidated, certainly in vivo. When studying the regulation of muscle mass by environmental hypoxia, many confounding factors have to be taken into account, such as decreased protein ingestion, sleep deprivation or reduced physical activity, which make difficult to know whether hypoxia per se causes a reduction in muscle mass.
\end{abstract}

Aim: We hypothesized that acute exposure to normobaric hypoxia (11\% $\mathrm{O}_{2}$ ) would repress the activation of the mTOR pathway usually observed after a meal and would activate the proteolytic pathways in skeletal muscle.

Methods: Fifteen subjects were exposed passively for $4 \mathrm{~h}$ to normoxic and hypoxic conditions in a random order after consumption of a light breakfast. A muscle biopsy and a blood sample were taken before, after 1 and $4 \mathrm{~h}$ of exposure.

Results: After $4 \mathrm{~h}$, plasma insulin concentration and the phosphorylation state of PKB and S6K1 in skeletal muscle were higher in hypoxia than in normoxia $(P<0.05)$. At the same time, Redd1 mRNA level was upregulated $(P<0.05)$, whilst MAFbx mRNA decreased $(P<0.05)$ in hypoxia compared with normoxia. Proteasome, cathepsin L and calpain activities were not altered by environmental hypoxia.

Conclusion: Contrary to our hypothesis and despite an increase in the mRNA level of Redd1, an inhibitor of the mTORC1 pathway, short-term acute environmental hypoxia induced a higher response of PKB and S6K1 to a meal, which may be due to increased plasma insulin concentration.

Keywords insulin, NIRS, PKB, proteasome, S6K1.
Hypoxia is a state of lowered oxygen tension $\left(\mathrm{PO}_{2}\right)$ in tissue that can be created by environmental conditions such as high altitude or by pathological conditions such as chronic obstructive pulmonary disease (Baldi et al. 2010), obstructive sleep apnoea (Garvey et al.
2009) and anaemia (Grocott et al. 2007). During exercise, hypoxia can also be generated but, contrary to the previous situations, oxygen restriction is then limited to skeletal muscle (Ameln et al. 2005). Whatever the origin of hypoxia, skeletal muscle cells will 
adapt acutely and/or chronically to deal with this reduction in oxygen availability. For example, patients exposed to chronic hypoxaemia due to lung disease have a higher 5-year mortality and an associated muscle wasting (Schols et al. 2005). Several studies revealed that highlanders and hikers undergo reductions in muscle fibre cross-sectional area, which is associated with increased capillarization (Hoppeler et al. 1990, MacDougall et al. 1991, Mizuno et al. 2008). Although contrasting results have been reported as well (Lundby et al. 2004), long-lasting hypoxia generally leads to a negative regulation of protein metabolism and a loss of muscle mass.

Studies on cell culture and animals have provided some more insight into the mechanisms by which hypoxia negatively regulates protein metabolism. In a general way, hypoxia suppresses ATP- and energyconsuming processes like $\mathrm{Na}^{+}, \mathrm{K}^{+}$ATPase activity or protein synthesis (Koumenis \& Wouters 2006). At a molecular level, a decrease in $\mathrm{PO}_{2}$ activates the hypoxia-inducible factor-1 alpha (HIF-1 $\alpha$ ), a transcription factor regulating the expression of genes involved in a large spectrum of functions, that is, angiogenesis, metabolic transition to anaerobic glycolysis and cell motility and invasion (Koumenis \& Wouters 2006). Whether HIF- $1 \alpha$ is directly responsible for the decrease in protein synthesis is unknown, but HIF- $1 \alpha$ and the mammalian target of rapamycin complex 1 (mTORC1) pathway, a key regulator of the mRNA translation machinery, have been shown to regulate each other (Cam et al. 2010, Greer et al. 2012, Lee et al. 2009). On the other hand, hypoxia has also been shown to inhibit mTORC1 in a HIF- $1 \alpha$-independent way in cell cultures (Arsham et al. 2003). Whether these observations from cell cultures, where very low concentrations of oxygen $\left(0-5 \% \mathrm{O}_{2}\right)$ are used, may be extrapolated to living organisms remains an open question.

Hypoxia inhibits mTORC1 through at least two intermediates: a small protein called 'regulated in development and DNA damage responses 1' (Redd1) (McGee \& Hargreaves 2010) as well as the critical regulator of energy balance 5' AMP-activated protein kinase (AMPK) (Liu et al. 2006). Both Redd1 (McGee \& Hargreaves 2010) and AMPK (Liu et al. 2006) inhibit mTORC1 through phosphorylation of the tuberous suppressor complex 2 (TSC2), which reinforces the inhibition of this complex on mTORC1. Inhibition of mTORC1 results in down-regulation of $5^{\prime}$-terminal oligopyrimidine tract (TOP) mRNA translation through decreased phosphorylation of p70 ribosomal S6 kinase 1 (S6K1) and eukaryotic initiation factor 4E-binding protein 1 (4E-BP1), thereby inhibiting the formation of the eukaryotic initiation factor $4 \mathrm{~F}$ (eIF4F) complex (Laplante \& Sabatini 2012). Hypoxia seems also to impinge directly on the formation of this complex by altering the availability of eukaryotic initiation factor 4E (eIF4E) (Koritzinsky et al. 2006).

Endoplasmic reticulum (ER) stress and its downstream response, the unfolded protein response, are mechanisms that have recently been proposed to participate in the reduction of protein synthesis under hypoxia (Koritzinsky et al. 2006). Three main sensors, each of which initiates a branch of the unfolded protein response, contribute separately or coordinately for restoration of ER homoeostasis; activating transcription factor 6 (ATF6), inositol-requiring enzyme 1 alpha $($ IRE1 $\alpha)$ and protein kinase RNA-like endoplasmic reticulum kinase (PERK). These three factors associate with the protein, chaperone binding protein (BiP) in normal physiological conditions. Under ER stress, ATF6, IRE1 $\alpha$ and PERK are released from BiP and may become activated (Ron \& Walter 2007). Severe hypoxia causes ER stress, as $\mathrm{O}_{2}$ serves as an electron acceptor during oxidative protein folding, an ER process driving formation of disulphide bonds in proteins (Tagliavacca et al. 2012). When $\mathrm{O}_{2}$ is insufficient, disulphide bonds cannot be formed, misfolded proteins accumulate, and the unfolded protein response is activated. However, the underlying molecular mechanisms are poorly understood (Wouters \& Koritzinsky 2008). Hypoxia has been shown to activate PERK, which in turn phosphorylates eukaryotic initiation factor $2 \alpha$ (eIF $2 \alpha)$ and inhibits translation initiation (Koumenis et al. 2002). The regulation of IRE $1 \alpha$ and ATF 6 by hypoxia has been less studied and requires further investigation.

Muscle protein degradation is a complex process implicating four systems: the lysosomal proteases (cathepsins), the calcium-dependent proteases (calpains), the caspases and the ubiquitin-proteasome pathway (Jackman \& Kandarian 2004). The latter mechanism is mainly regulated by E3 ligases amongst which are muscle atrophy $\mathrm{F}$ box (MAFbx) and muscle ring finger protein-1 (MuRF-1) (Bodine et al. 2001). The transcriptional regulation of MAFbx and MuRF1 is controlled by, amongst others, the members of the forkhead FoxO family, themselves regulated by protein kinase B (PKB also called Akt) (Stitt et al. 2004). To the best of our knowledge, the effect of hypoxia on protein degradation has not been studied in human skeletal muscle.

When studying the regulation of muscle mass by environmental hypoxia, many confounding factors have to be taken into account. Long-term hypoxia at extreme altitude is known to reduce appetite and energy intake, to disturb the sleep cycle and to reduce physical activity, thereby indirectly favouring a catabolic state. It is thus difficult to determine whether the reduction in muscle mass observed after long-term exposure to 
hypoxia is due to decreased dietary protein ingestion, sleep deprivation, cold exposure and reduced physical activity or to other mechanisms of regulation. Most of the studies focusing on the regulation of protein metabolism by acute hypoxia have used an exercise paradigm. However, muscle contractile activity per se is known to alter oxygen availability, thereby potentially indirectly affecting protein metabolism and adding one supplemental confounding factor. By simulating high altitude in a hypoxic facility, we were able to standardize the nutritional and the physical activity status of the subjects and to study more directly the acute effect of hypoxia on muscle protein metabolism. The purpose of this study was thus to determine at a molecular level how acute environmental hypoxia regulates protein synthesis and breakdown in resting human skeletal muscle. Based on previous studies reporting a negative effect of hypoxia on muscle protein balance (Hoppeler et al. 1990, MacDougall et al. 1991, Mizuno et al. 2008), we hypothesized that hypoxia would repress the response to a breakfast by inhibiting key regulators of protein synthesis and by stimulating protein breakdown.

\section{Materials and methods}

\section{Subjects}

Fifteen healthy young men (age $21.3 \pm 0.4$ years; BMI $21.8 \pm 0.45 \mathrm{~kg} \mathrm{~m}^{-2}$ ) volunteered to participate in this study, which was approved by the local Ethics Committee (KU Leuven) and was in conformity with the Helsinki Declaration. The subjects were all physically active, but they were not involved in any specific resistance training programme during the period of the study. Subjects were asked to refrain from vigorous physical activity for 2 days, as well as to abstain from alcohol consumption the day before the experiments. Furthermore, they were not exposed for more than 7 days to an altitude above $1500 \mathrm{~m}$ within a period of 3 months preceding the start of the study. A medical check-up was carried out to detect any contraindications for exposure to extreme altitude, and written consent was obtained from all subjects after explaining all potential risks of the study.

\section{Study design}

All subjects underwent two experimental sessions in a randomized crossover designed order, with a 4-week interval period in between. In the normoxic trial (NOR), participants were exposed to normal atmospheric conditions $\left(20.9 \% \mathrm{O}_{2}\right)$. In the hypoxic trial (HYP), participants inspired hypoxic air (approx. $\left.11 \pm 0.1 \% \mathrm{O}_{2}\right)$.
Normoxic trial. The night before the experimental session, subjects received a standardized dinner $(58 \%$ carbohydrates, $28 \%$ fat and $14 \%$ protein). After an overnight fast of at least $8 \mathrm{~h}$, participants reported to the laboratory at 6:00-8:30 am where they received a standardized breakfast $165 \%$ carbohydrates, $29 \%$ fat and $6 \%$ protein, total energy intake ranged from 489.0 to $671.5 \mathrm{kcal}$ according to the individual weight of the subjects). We chose to study the effect of environmental hypoxia after a light meal and not in the fasted state because we expected that hypoxia would create a state of anabolic resistance rather than impair basal protein metabolism. After breakfast completion, a first near-infrared spectroscopy (NIRS) measurement (Hamamatsu NIRO 200, Louvainla-Neuve, Belgium) of $20 \mathrm{~min}$ was performed to evaluate muscle oxygenation status via the tissue oxygenation index (TOI), which is a valid parameter to assess the fraction of $\mathrm{O}_{2}$-saturated tissue haemoglobin and myoglobin content (Ferrari et al. 2004). One pair of NIRS probes, consisting of one light emitter and one light detector, was attached on the belly of the right $\mathrm{m}$. vastus lateralis in parallel with the long axis of the muscle. We used the right leg for the NIRS measurements because the left leg was used for muscle biopsies. Before positioning of the probes, the skin was shaved to exclude interaction of hair as a chromophore. Forty minutes after completion of the breakfast (T0), a first biopsy sample, with the needle pointing proximally, was taken from the left $\mathrm{m}$. vastus lateralis under local anaesthesia (1-2 mL Lidocaine) through a $5-\mathrm{mm}$ incision in the skin. Immediately after, a blood sample was taken from an antecubital vein. After the baseline measurements, which were all taken in normoxic conditions, subjects were transferred to the air-conditioned (approx. $21^{\circ} \mathrm{C}$ ) hypoxic facility (Sporting Edge, Leicestershire, $\mathrm{UK})$, yet maintained at $20.9 \% \mathrm{O}_{2}$, where they rested in the seated position for $4 \mathrm{~h}$ whilst reading books or watching a movie. Immediately after entering the room, blood oxygen saturation $\left(\mathrm{SpO}_{2}\right)$ was measured with a pulse oximeter (Oximax, Nellcor, UK). One hour after the first biopsy (T60), a second biopsy was taken through the same incision as the first, yet with the needle pointing distally. Furthermore, a venous blood sample was taken. At T220, a second 20-min NIRS measurement was performed. Finally, at T240, the last biopsy and blood sample were taken. The last biopsy was taken with the needle pointing distally and through a new incision in the skin $3 \mathrm{~cm}$ distally to the first incision.

Hypoxic trial. All experimental conditions in the hypoxic trial were similar to those in the normoxic trial except that the hypoxic facility was maintained at $11 \%$ 
ambient $\mathrm{O}_{2}$ content (approx. $5000 \mathrm{~m}$ altitude) instead of $20.9 \%$.

\section{Western blot}

Details of the immunoblotting procedures have been described previously (Deldicque et al. 2010b). Briefly, frozen muscle tissue (approx. $20 \mathrm{mg}$ ) was homogenized $3 \times 5 \mathrm{~s}$ with a Polytron mixer in ice-cold buffer $(1: 10, w / v) \quad[50 \mathrm{~mm}$ Tris- $\mathrm{HCl}$ pH 7.0, $270 \mathrm{~mm}$ sucrose, $5 \mathrm{~mm}$ EGTA, $1 \mathrm{~mm}$ EDTA, $1 \mathrm{~mm}$ sodium orthovanadate, $50 \mathrm{~mm}$ glycerophosphate, $5 \mathrm{~mm}$ sodium pyrophosphate, $50 \mathrm{~mm}$ sodium fluoride, $1 \mathrm{~mm}$ DTT, $0.1 \%$ Triton-X 100 and a complete protease inhibitor tablet (Roche Applied Science, Vilvoorde, Belgium)]. Homogenates were then centrifuged at $10000 \mathrm{~g}$ for $10 \mathrm{~min}$ at $4^{\circ} \mathrm{C}$. The supernatant was collected and immediately stored at $-80{ }^{\circ} \mathrm{C}$. The protein concentration was measured using the DC protein assay kit (Bio-Rad laboratories, Nazareth, Belgium). $30-80 \mu \mathrm{g}$ of proteins was separated by SDSPAGE $(8-12 \%$ gels) and transferred to PVDF membranes. Subsequently, membranes were blocked with $5 \%$ non-fat milk for $1 \mathrm{~h}$ and afterwards incubated overnight $\left(4^{\circ} \mathrm{C}\right)$ with the following antibodies (1 : 1000, Cell Signaling, Leiden, the Netherlands): phospho-Akt/PKB Ser ${ }^{473}$, Akt/PKB pan, total eEF2, phospho-S6K1 $\mathrm{Thr}^{389}$, total S6K1, phospho-4E-BP1 $\mathrm{Thr}^{37 / 46}$, total 4E-BP1, p-FoxO1 $\mathrm{Thr}^{24} /$ FoxO3a $\mathrm{Thr}^{32}$, total FoxO3a, p-eIF $2 \alpha$ Ser $^{51}$, total eIF $2 \alpha$, BiP, C/EBP homologous protein (CHOP) and HIF- $1 \alpha$. Horseradish peroxidase-conjugated anti-mouse $(1: 10$ 000), antirabbit $(1: 5000)$ or anti-goat $(1: 20$ 000) secondary antibodies (Sigma-Aldrich, Bornem, Belgium) were used for chemiluminescent detection of proteins. Membranes were scanned and quantified with Genetools and Genesnap softwares (Syngene, Cambridge, UK) respectively. Then, membranes were stripped and reprobed with the antibody for the total form of the respective protein to ascertain the relative amount of the phosphorylated protein compared with the total form throughout the whole experiment. The results are presented as the ratio protein of interest/eEF2 or as the ratio phosphorylated/total forms of the proteins when the phosphorylation status of the protein was measured. A value of 1.0 was assigned to the mean value of the first sample (T0) in NOR and in HYP to which all other values from the respective condition were reported.

\section{RNA extraction and reverse transcription}

The method used for reverse transcription is described in detail elsewhere (Jamart et al. 2011, Vincent et al. 2010). Briefly, total RNA was extracted using TRIzol
(Invitrogen, Vilvoorde, Belgium) from 20-25 mg of frozen muscle tissue. RNA quality and quantity were assessed by spectrophotometry with a Nanodrop (Thermo Scientific, Erembodegem, Belgium). One $\mu \mathrm{g}$ of RNA was reverse-transcribed using the HighCapacity cDNA Reverse Transcription kit (Applied Biosystems, Gent, Belgium) according to manufacturer's instructions.

\section{Real-time $q P C R$ analysis}

A SYBR Green-based master mix (Applied Biosystems) was used for real-time PCR analyses using the ABI PRISM 7300 (Applied Biosystems). Real-time PCR primers were designed for human MuRF-1, MAFbx, Bcl-2/adenovirus E1B $19 \mathrm{kDa}$ protein-interacting protein 3 (Bnip3), activating transcription factor 4 (ATF4), spliced XBP1 (XBP1s), CHOP, HIF-1 $\alpha$ and Redd1 (Table 1). Thermal cycling conditions consisted of 40 three-step cycles including denaturation of $30 \mathrm{~s}$ at $95{ }^{\circ} \mathrm{C}$, annealing of $30 \mathrm{~s}$ at $58^{\circ} \mathrm{C}$ and extension of $30 \mathrm{~s}$ at $72{ }^{\circ} \mathrm{C}$. All reactions were performed in duplicate. To compensate for variations in input RNA amounts and efficiency of reverse transcription, cyclophilin A (Cyclo A) and beta-2-microglobulin $(\beta-2-M G)$ mRNA were quantified, and results were normalized to these values. These genes were chosen out of five normalization genes using the GeNorm applet according to the guidelines and theoretical framework described elsewhere (Vandesompele et al. 2002). A value of 1.0 was assigned to the mean value of the first sample (T0) in NOR and in HYP to which all other values from the respective condition were reported.

\section{Enzymatic activity assays}

Enzymatic activities were determined fluorometrically using specific substrates and specific inhibitors. Each sample was assessed in triplicate with one replicate containing a specific inhibitor to the activity studied. 26S $\beta 5$ subunit proteasome activity was determined by adding $100 \mu \mathrm{M}$ Suc-LLVY-AMC (Calbiochem) to $10 \mu \mathrm{g}$ proteins in a reaction buffer containing $50 \mathrm{~mm}$ Tris, pH 7.5, $1 \mathrm{~mm}$ EDTA, $150 \mathrm{~mm} \mathrm{NaCl}$, $5 \mathrm{~mm} \mathrm{MgCl}_{2}, \quad 0.5 \mathrm{~mm}$ DTT and $100 \mu \mathrm{M}$ ATP, $\pm 20 \mu \mathrm{M}$ epoxomicin. Cathepsin L activity was determined by adding $100 \mu \mathrm{M}$ Z-Phe-Arg-AMC (Peptide Institute, Sandhausen, Germany) to $10 \mu \mathrm{g}$ proteins in a buffer containing $100 \mathrm{~mm}$ sodium acetate, $\mathrm{pH}$ 5.5, $1 \mathrm{~mm}$ EDTA, $1 \mathrm{~mm}$ DTT, $\pm 10 \mu \mathrm{M}$ cathepsin L inhibitor I (Calbiochem, Overijse, Belgium). Calpain activity was determined by adding $200 \mu \mathrm{M}$ SucLLVY-AMC (Calbiochem) to $10 \mu \mathrm{g}$ proteins in a buffer containing $25 \mathrm{~mm}$ Tris, pH7.5, $0.5 \mathrm{~mm}$ 
Table I Primer sequences

\begin{tabular}{lll}
\hline & Forward & Reverse \\
\hline ATF4 & CCA ACA ACA GCA AGG AGG ATG & GTC ATC CAA CGT GGT CAG AAG G \\
Bnip3 & CTG AAA CAG ATA CCC ATA GCA TT & CCG ACT TGA CCA ATC CCA \\
CHOP & CTG GCT TGG CTG ACT GAG GAG & CGG GCT GGG GAA TGA CC \\
HIF-1 $\alpha$ & GCC CCA GAT TCA GGA TCA GA & TGG GAC TAT TAG GCT CAG GTG AAC \\
Redd1 & TGA GGC ACG GAG TGG GAA & CAG CTC GAA GTC GGG CAA \\
MuRF-1 & AAA CAG GAG TGC TCC AGT CGG & CGC CAC CAG CAT GGA GAT ACA \\
MAFbx & CCC AAG GAA AGA GCA GTA TGG AGA & GGG TGA AAG TGA AAC GGA GCA \\
XBP1s & CCG CAG CAG GTG CAG G & GAG TCA ATA CCG CCA GAA TCC A \\
Cyclo A & CTT CAT CCT AAA GCA TAC GGG TC & TGC CAT CCA ACC ACT CAG TCT \\
$\beta-2-\mathrm{MG}$ & ATG AGT ATG CCT GCC GTG TGA & GGC ATC TTC AAA CCT CCA TG
\end{tabular}

ATF4, activating transcription factor 4; Bnip3, Bcl-2/adenovirus E1B $19 \mathrm{kDa}$ protein-interacting protein 3; CHOP, C/EBP homologous protein; HIF- $1 \alpha$, hypoxia-inducible factor-1 alpha; Redd1, regulated in development and DNA damage responses 1 ; MuRF-1, muscle ring finger protein-1; MAFbx, muscle atrophy F box; XBP1s, spliced X-box binding protein 1; Cyclo A, cyclophilin A; $\beta$-2-MG, beta-2-microglobulin.

EDTA, $5 \mathrm{~mm} \mathrm{CaCl}_{2}, 75 \mathrm{~mm} \mathrm{NaCl}, 0.025 \mathrm{~mm}$ DTT, $\pm 125 \mu \mathrm{M}$ calpain inhibitor IV (Calbiochem). Fluorescence was monitored every $5 \mathrm{~min}$ for $105 \mathrm{~min}$ on a fluorometer (Fluostar Optima, BMG labtech, SintPieters-Leeuw, Belgium) at an excitation and emission wavelengths of 370 and $460 \mathrm{~nm}$ respectively. Enzymatic activities were calculated as the difference of the slope of the accumulation of fluorescence as a function of time in the absence of inhibitor and presence of inhibitor.

\section{Analysis of blood samples}

Plasma insulin and cortisol were assayed by chemiluminescence using the Siemens DPC kit according to the instructions of the manufacturer. Blood glucose was measured with a Glucocard X-Meter (Arkray, Kyoto, Japan).

\section{Statistical analyses}

A repeated-measures ANOVA design was used to assess the statistical significance of differences between mean values over time and between conditions. When appropriate, Holm-Sidak pairwise multiple comparison test was used as post hoc. A Pearson correlation coefficient was calculated between $\Delta \mathrm{SpO}_{2}$ and $\Delta$ TOI values. The threshold of significance was set at 0.05 . Results are expressed as the means \pm SEM.

\section{Results}

\section{Blood oxygen saturation/tissue oxygenation index}

$\mathrm{SpO}_{2}$. Mean $\mathrm{SpO}_{2}$ was markedly lower $(-25 \%)$ in HYP than in NOR during the whole experimental trial $(P<0.05$, Table 2$)$. Individual decreases in HYP compared with NOR ranged from 12 to $36 \%$.

TOI. There were no differences in TOI between T0 and T240 in the NOR trial. Conversely, during the HYP trial, TOI values were approx. $6 \%$ lower at T240 than at T0 $(P<0.05$, Table 2$)$. A correlation of $r=0.451$ was found between $\Delta \mathrm{SpO}_{2}\left[\left(\mathrm{SpO}_{2}\right.\right.$ NOR T240-SpO 2 NOR To $)-\left(\mathrm{SpO}_{2}\right.$ HYP T240-SpO 2 HYP To $\left.)\right]$ and $\Delta$ TOI [(TOI NOR T240-TOI NOR T0)-(TOI HYP T240TOI HYP т0)] $(P<0.05$, data not shown).

\section{Blood biochemistry}

Insulin. Plasma insulin levels decreased throughout the experiment in both NOR and HYP $(P<0.05$,

Table 2 Arterial oxygen saturation and tissue oxygenation index values

\begin{tabular}{|c|c|c|}
\hline & & $\begin{array}{l}\text { Mean during } \\
\text { whole experiment }\end{array}$ \\
\hline \multicolumn{3}{|c|}{$\mathrm{SpO}_{2}(\%)$} \\
\hline NOR & & $99.0 \pm 0.2$ \\
\hline \multirow[t]{2}{*}{ HYP } & & $75.5 \pm 2.0^{*}$ \\
\hline & T0 & $\mathrm{T} 240$ \\
\hline \multicolumn{3}{|c|}{ TOI (\%) } \\
\hline NOR & $69.7 \pm 1.5$ & $68.4 \pm 1.2$ \\
\hline HYP & $70.8 \pm 2.0$ & $65.7 \pm 1.4^{\dagger}$ \\
\hline \multicolumn{3}{|c|}{$\begin{array}{l}\text { Mean arterial oxygen saturation }\left(\mathrm{SpO}_{2}\right) \text { during the whole } \\
\text { experiment and tissue oxygenation index (TOI) at the start } \\
\text { (T0) and at the end (T240) of the experimental session in } \\
\text { either normoxia (NOR) or hypoxia (HYP). Values are } \\
\text { means } \pm \text { SEM }(n=15) \text {. } \\
" P<0.05 \text { vs. NOR; } \\
{ }^{\dagger} P<0.05 \text { vs. T0. }\end{array}$} \\
\hline
\end{tabular}


Table 3) with a larger decrease observed in NOR, resulting in approx. 2-fold lower plasma insulin values in NOR compared with HYP at T240 $(P<0.05)$.

Glucose. Blood glucose increased by $15 \%$ from T0 to T60 in NOR $(P<0.05)$ but not in HYP, resulting in lower glucose concentrations in HYP compared with NOR at T60 $(P<0.05)$. At 240 , glucose values were similar to those at T0 in both NOR and HYP.

Cortisol. Plasma cortisol levels increased by about $30 \%$ between T0 and T240 in NOR and in HYP $(P<0.05$, Table 3$)$. No differences were present between NOR and HYP.

\section{Effect of environmental hypoxia on the regulation of protein synthesis}

Phosphorylation of PKB at Ser ${ }^{473}$ decreased from T0 to T240 in NOR $(P<0.05)$, but not in HYP (Fig. 1a), resulting in a approx. $40 \%$ lower phosphorylation of $\mathrm{PKB}$ in NOR compared with HYP at T240 $(P<0.05)$. Downstream of PKB and mTORC1, phosphorylation of S6K1 at $\mathrm{Thr}^{389}$ followed a similar phosphorylation pattern as PKB (Fig. 1b), but the reduction in phosphorylation was more pronounced than for PKB in both NOR and HYP $(P<0.05)$. Like phospho-PKB, phospho-S6K1 was lower in NOR compared with HYP at T240 $(P<0.05)$. Phosphorylation of 4E-BP1 at $\mathrm{Thr}^{37 / 46}$ (Fig. 1c), another downstream target of mTORC1, was not affected by any condition. We also measured the mRNA level of Redd 1 as the latter is known to inhibit the mTOR pathway and to be up-regulated during hypoxia (Sch-

Table 3 Plasma insulin, blood glucose and plasma cortisol concentrations

\begin{tabular}{|c|c|c|c|}
\hline & T0 & $\mathrm{T} 60$ & T240 \\
\hline \multicolumn{4}{|c|}{ Insulin $\left(\mu \mathrm{U} \mathrm{mL}^{-1}\right)$} \\
\hline NOR & $27.3 \pm 3.6$ & $20.9 \pm 3.6$ & $5.9 \pm 1.2^{* \dagger}$ \\
\hline HYP & $31.5 \pm 4.3$ & $17.9 \pm 3.3^{*}$ & $13.4 \pm 2.5^{* *}$ \\
\hline \multicolumn{4}{|c|}{ Glucose $\left(\mathrm{mg} \mathrm{dL}^{-1}\right)$} \\
\hline NOR & $94.2 \pm 2.5$ & $110.1 \pm 5.4^{*}$ & $81.6 \pm 2.0^{\dagger}$ \\
\hline HYP & $86.0 \pm 4.0$ & $89.5 \pm 4.7^{*}$ & $87.7 \pm 2.8$ \\
\hline \multicolumn{4}{|c|}{ Cortisol (nM) } \\
\hline NOR & $257.8 \pm 13.1$ & $305.9 \pm 20.5$ & $337.9 \pm 16.7^{*}$ \\
\hline HYP & $234.9 \pm 14.9$ & $310.6 \pm 24.3^{*}$ & $325.9 \pm 29.9^{*}$ \\
\hline
\end{tabular}

Plasma insulin, blood glucose and plasma cortisol concentrations at basal (T0), after $1 \mathrm{~h}$ (T60) and after $4 \mathrm{~h}$ (T240) in normoxia (NOR) or in hypoxia (HYP). Values are means \pm SEM $(n=15)$.

$* P<0.05$ vs. T0;

${ }^{\dagger} P<0.05$ vs. T60;

${ }^{\sharp} P<0.05$ vs. NOR. warzer et al. 2005). There was a trend to increase in the mRNA level of Redd1 during both experimental trials, but this increase was only significant in HYP (T240, approx. fourfold increase vs. basal and approx. twofold increase vs. NOR, $P<0.05$, Fig. 1d).

\section{Effect of environmental hypoxia on the regulation of protein breakdown}

Activities of $26 \mathrm{~S}$ proteasome $\beta 5$, cathepsin $\mathrm{L}$ and calpain, which have been previously described as key proteins in muscle protein degradation (Jackman \& Kandarian 2004), were assessed by fluorometric assays. Compared with T0, activity of $26 \mathrm{~S}$ proteasome $\beta 5$ increased by $19 \%$ in NOR at T240 $(P<0.05$, Fig. 2a). No time effect was observed in HYP. Cathepsin L and calpain activities showed the same activation pattern, although the statistical threshold was not reached (time effect for cathepsin L, $P=0.089$, Fig. 2b; time effect for calpain, $P=0.056$, Fig. 2c). The activity of the proteasome is regulated by E3 ligases, the two best described of which in skeletal muscle are MAFbx and MuRF-1 (Bodine et al. 2001). Their expressions are under the control of a family of transcription factors called FoxO (Stitt et al. 2004). Phosphorylation of FoxO1/3a at $\mathrm{Thr}^{24 / 32}$ was higher at T60 and T240 than at basal in NOR $(P<0.05)$, but not in HYP (Fig. 2d). No differences between conditions were present. Neither MAFbx nor MuRF-1 mRNA expression followed the phosphorylation of FoxO1/3a. The mRNA levels of MuRF-1 were up-regulated by approx. $15 \%$ at T240 in HYP $(P<0.05$, Fig. 2e). MAFbx mRNA content decreased throughout the experiment in both NOR and HYP. However, the decrease was larger in HYP compared with NOR $(P<0.05$, Fig. 2f). Bnip3 mRNA expression, a marker of the autophagy/lysosome pathway (Tracy et al. 2007), was not modified by the experimental conditions (Fig. 2g).

\section{Effect of environmental hypoxia on the unfolded protein response}

Activation of the unfolded protein response, triggered by endoplasmic reticulum stress, was assessed by measuring several markers previously described (Deldicque et al. 2010a). ATF4 and spliced XBP1 mRNA contents increased at T240 compared with T0 but only in HYP (by $30 \%$ for ATF4 and by $25 \%$ for XBP1s, $P<0.05$, Fig. 3a,b). Moreover, the mRNA expression of ATF4 was approx. 30\% higher in HYP compared with NOR at T240 $(P<0.05$, Fig. 3a). BiP expression increased throughout the experiment in both conditions, but this increase was only significant in NOR at T240 $(P<0.05$, Fig. 3e). CHOP protein expression 

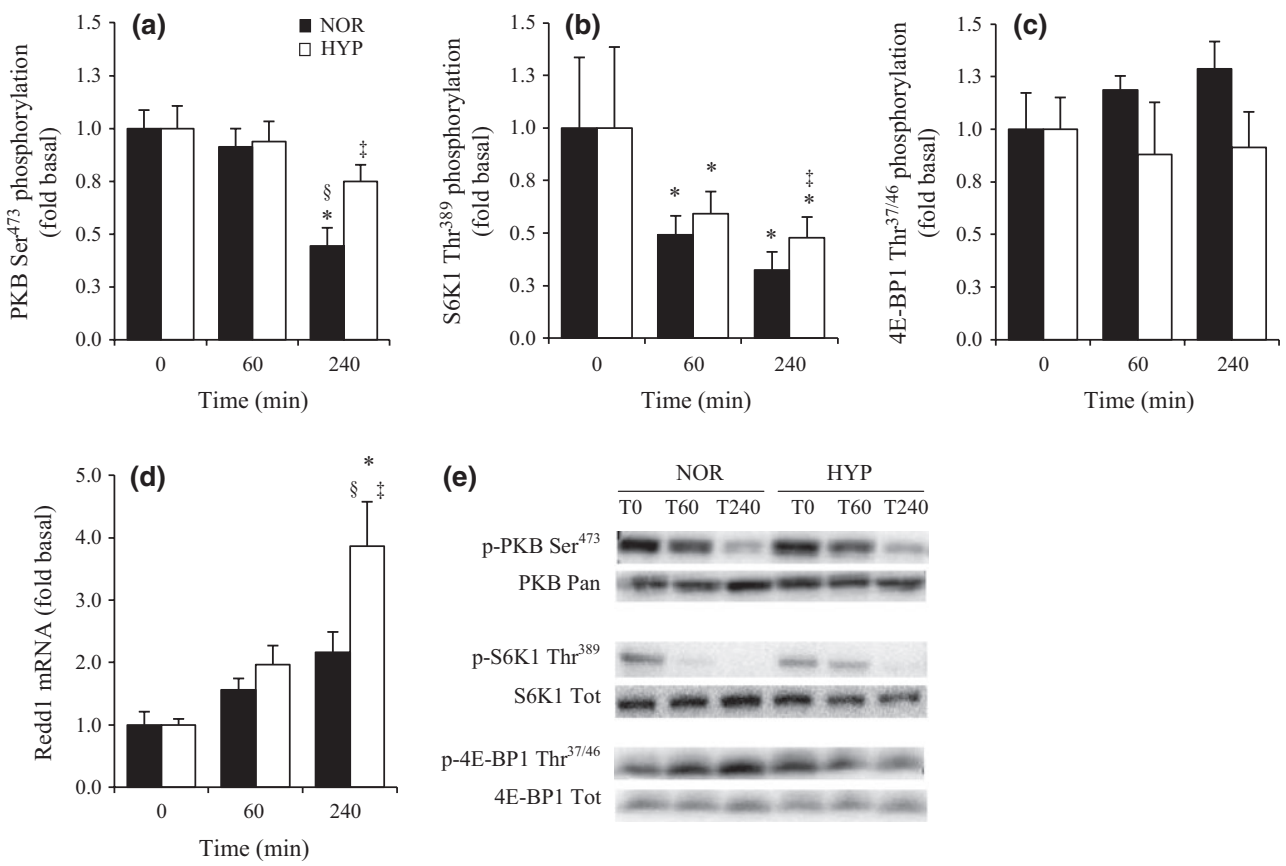

(e)

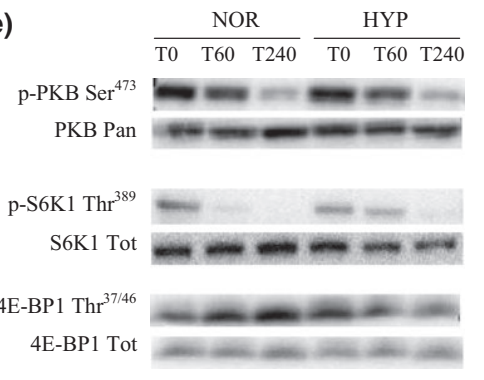

Figure I Effect of hypoxia on protein synthesis markers and regulators. (a) PKB, (b) S6K1, (c) 4E-BP1 phosphorylation and (d) Redd1 mRNA level at basal (0), after $1 \mathrm{~h} \mathrm{(60)}$ and after $4 \mathrm{~h} \mathrm{(240)}$ in normoxia (NOR) or in hypoxia (HYP). (e) Representative blots. Data shown are expressed as means \pm SEM $(n=15) .{ }^{*} P<0.05$ vs. T0; ${ }^{\S} P<0.05$ vs. T60; ${ }^{\ddagger} P<0.05$ vs. NOR.

tended to display a time effect $(P=0.075)$ with a tendency to higher CHOP expression in HYP compared with NOR at T60 $(P=0.055$, Fig. $3 \mathrm{~d})$. No effects were found in CHOP mRNA (Fig. 3c) or eIF $2 \alpha$ phosphorylation at $\operatorname{Ser}^{51}$ (Fig. 3f).

\section{Hypoxia-inducible factor-I and its downstream targets}

The acute bout of hypoxia did not alter HIF- $1 \alpha$ either at the mRNA level or at the protein level (Fig. 4), neither did it activate the transcriptional activity of HIF- $1 \alpha$. To test the latter, we measured the expression of several genes known to be regulated by HIF- $1 \alpha$. Neither GLUT-1 nor GAPDH mRNA levels were modified in HYP (data not shown). VEGF-A mRNA was the only one to increase in HYP. At T240, VEGF-A mRNA content was approx. 1.5-fold higher in HYP compared with NOR $(P<0.05$, Fig. 4b). We tried to quantify HIF- $1 \alpha$ at the protein level. However, the basal expression in normoxia was barely detectable, and hypoxia did not increase its expression (Fig. 4c). To ensure that our antibody was able to detect modifications in the protein levels, we treated human umbilical vein endothelial cells (HUVEC) with $1 \mathrm{~mm}$ dimethyloxalylglycine (DMOG), an inhibitor of the prolyl-hydroxylases to provoke accumulation of

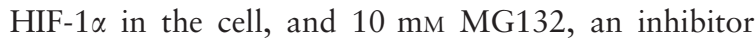
of the proteasome to block the degradation of HIF- $1 \alpha$. We were able to reproduce the results presented in the datasheet of the antibody (Cell Signaling), that is, no increase in HIF- $1 \alpha$ in MG-132-treated cells but a large increase in DMOG-treated cells, confirming thereby that if there had been any increase in muscle HIF- $1 \alpha$ expression, we should have detected it in our conditions. Altogether, our results show that the muscle HIF- $1 \alpha$ pathway was not activated by acute environmental hypoxia and, thus, that the effects observed in this study are probably HIF- $1 \alpha$-independent. However, we did not separate membrane and cytosolic cell fractions. We can thus not rule out a possible translocation of HIF- $1 \alpha$ to the cell nucleus. If this was the case, it did not result in higher transcriptional activity as measured by unchanged levels of mRNA known to be up-regulated by HIF- $1 \alpha$.

\section{Discussion}

Hypoxia-induced muscle wasting has been previously described as a consequence of high altitude (Hoppeler et al. 1990, MacDougall et al. 1991, Mizuno et al. 2008) and several diseases (Grocott et al. 2007, Wust \& Degens 2007), but the molecular mechanisms behind this loss of muscle mass are far to be elucidated. Contrary to our hypothesis and to previous reports on long-term environmental hypoxia, we show in the present study that acute and severe hypoxia alters the mTORC1 pathway in a way that is theoretically favourable for muscle protein accretion. 

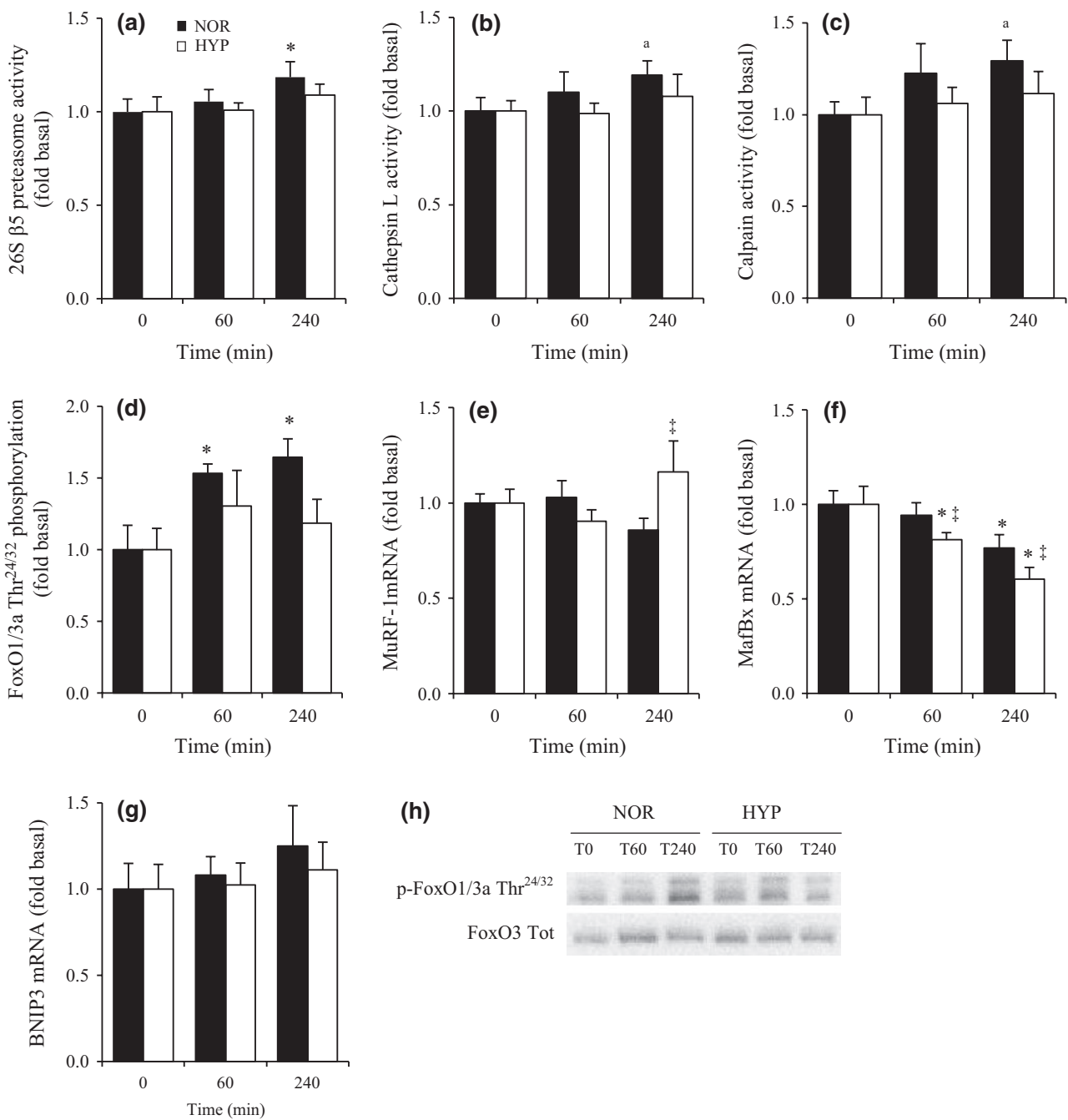

(h)

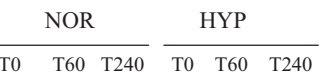

p-FoxO1/3a $\mathrm{Thr}^{24 / 32}$

FoxO3 Tot

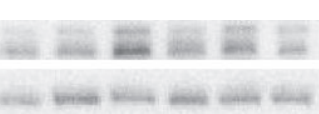

Figure 2 Effect of hypoxia on protein breakdown markers and regulators. (a) $26 \mathrm{~S} \beta 5$ proteasome activity, (b) cathepsin L activity, (c) calpain activity, (d) FoxO1/3a phosphorylation, (e) MuRF-1, (f) MAFbx and (g) Bnip3 mRNA levels at basal (0), after $1 \mathrm{~h} \mathrm{(60)}$ and after $4 \mathrm{~h}(240)$ in normoxia (NOR) or in hypoxia (HYP). (h) Representative blots. Data shown are expressed as means $\pm \operatorname{SEM}(n=15)$. $* P<0.05$ vs. T0; ${ }^{a} P<0.1$ vs. T0; ${ }^{\star} P<0.05$ vs. NOR.

\section{Up-regulation of the mTORCI pathway by environmental hypoxia}

Whereas it is generally accepted that hypoxia induces muscle wasting, there is clearly a lack of data describing the molecular mechanisms in human. Muscle wasting reflects a decrease in protein synthesis, an increase in protein breakdown or both at the same time. Only very few studies have attempted to clarify the molecular mechanisms by which acute or more prolonged environmental hypoxia regulates muscle mass in human. A slight decrease in total mTORC1 was found after 7- to 9-day sojourn at $4559 \mathrm{~m}$ (Vigano et al. 2008). In another recent study, subjects showed a blunted exercise-induced increase in muscle protein synthesis when breathing hypoxic air $(12 \%$
$\mathrm{O}_{2}$ ) compared with normoxic air (Etheridge et al. 2011). Hypoxia did not modify phosphorylation of S6K1 or expression of Redd1 whether at rest or after exercise. In another study, in rat soleus muscle, Redd1 expression was markedly increased, and the $\mathrm{PKB} / \mathrm{mTORC} 1$ pathway was concomitantly downregulated after a 3-week exposure to $6300 \mathrm{~m}$. Furthermore, in hypoxemic patients suffering from chronic obstructive pulmonary disease, a substantial decrease in phosphorylation of several intermediates of the PKB/mTORC1 pathway was reported (Favier et al. 2010). In contrast to the aforementioned studies, our data show that PKB and S6K1 displayed a higher phosphorylation state after 4-h exposure to hypoxia following a meal. All biopsies were taken after a light meal explaining why PKB and S6K1 

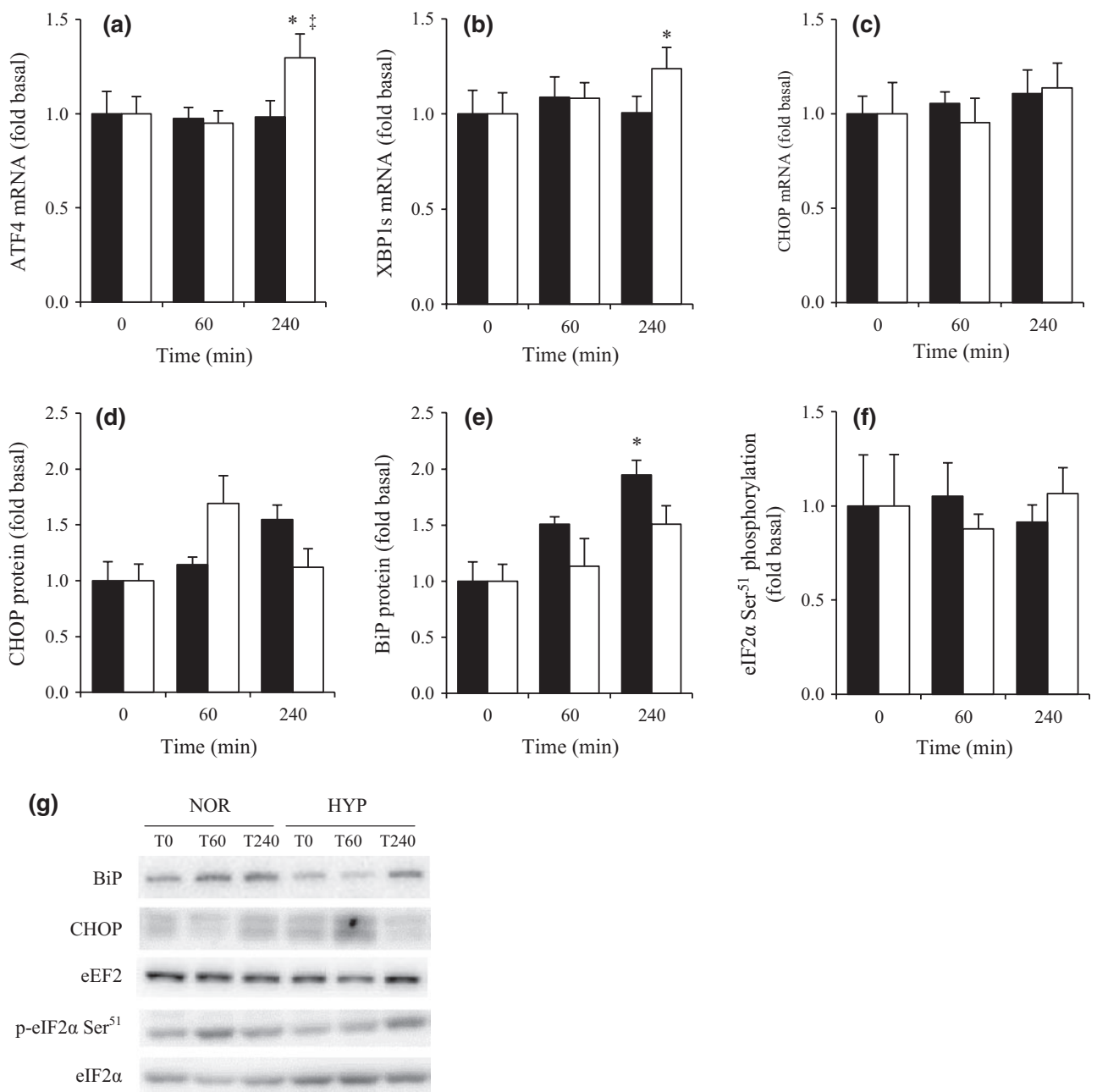

Figure 3 Effect of acute hypoxia on markers of the unfolded protein response. (a) ATF4, (b) XBP1s and (c) CHOP mRNA levels, (d) CHOP and (e) BiP protein expressions and (f) eIF2 $\alpha$ phosphorylation at basal (0), after $1 \mathrm{~h} \mathrm{(60)}$ and after $4 \mathrm{~h} \mathrm{(240)}$ in normoxia (NOR) or in hypoxia (HYP). (g) Representative blots. Data shown are expressed as means \pm SEM $(n=15)$. $* P<0.05$ vs. $\mathrm{T} 0 ;{ }^{\circledR} P<0.05$ vs. NOR.

phosphorylation decreased between the first and the third biopsy in normoxia and hypoxia. In hypoxia, however, the return to basal phosphorylation states was slowed down for both proteins. When subjects remained fasted for $3.5 \mathrm{~h}$ in hypoxia, S6K1 phosphorylation was not changed compared with pre-exposure (Etheridge et al. 2011), indicating that short-term hypoxia does not modify basal phosphorylation of S6K1. Based on our data, it is however likely that environmental hypoxia alters the response of S6K1 and PKB to a meal. According to previous in vitro studies (Koritzinsky et al. 2006), we could have expected a down-regulation of 4E-BP1 phosphorylation due to hypoxia. However, such increase did not occur. We choose to use an antibody specific to $\mathrm{Thr}^{37}$ and $\mathrm{Thr}^{46}$, the sites phosphorylated by mTORC1 as the aim of the study was to focus on the mTORC1 pathway. However, $\mathrm{Thr}^{37}$ and $\mathrm{Thr}^{46}$ are also known to be less sensitive to serum and other growth factors than other sites of the protein, for example $\mathrm{Thr}^{65}$ and $\mathrm{Thr}^{70}$ (Gingras et al. 1999). We can thus not rule out that other sites of 4E-BP1, more sensitive to changes in insulin concentrations in vivo, reacted the same way as PKB and S6K1. However, it is difficult to screen each of them as six different sites (Thr 37, Thr 46, Ser 65, Thr 70, Ser 83 and Ser 112) have been discovered up to now (Gingras et al. 2001).

\section{Redd-I expression is regulated by HIF-I $\alpha$-independent mechanisms}

Redd-1 was originally discovered in cell cultures as a hypoxia-responsive gene (Shoshani et al. 2002), and since then, many studies have confirmed that Redd-1 is a direct target of the transcription factor HIF- $1 \alpha$ 

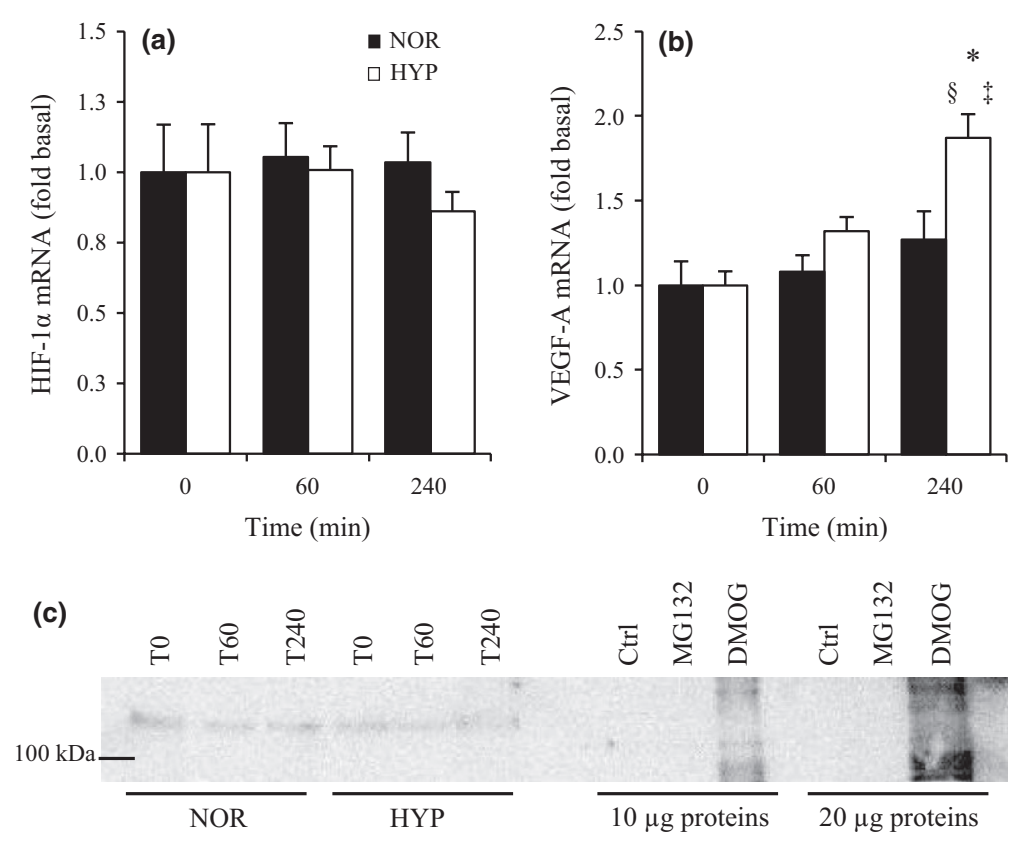

Figure 4 Effect of acute hypoxia on the hypoxia-inducible factor pathway. (a) HIF-1 $\alpha$ mRNA level (b) VEGF-A mRNA level at basal (0), after $1 \mathrm{~h}(60)$ and after $4 \mathrm{~h}(240)$ in normoxia (NOR) or in hypoxia (HYP). (c) Representative western blot for HIF$1 \alpha$ from one subject and the different controls we used on HUVEC cell cultures (see material and methods for further details). Data shown are expressed as means \pm SEM $(n=15) .{ }^{*} P<0.05$ vs. T0; ${ }^{\S} P<0.05$ vs. T60; ${ }^{\ddagger} P<0.05$ vs. NOR.

(Schwarzer et al. 2005). It has also been shown to act as an inhibitor of mTORC1 through regulation of 143-3 protein shuttling (DeYoung et al. 2008). Here, we show a clear elevation of Redd-1 mRNA after $4 \mathrm{~h}$ of exposure to hypoxia against the face of constant HIF$1 \alpha$. We did not assessed Redd-1 at the protein level, but it has previously been shown that the mRNA and protein expressions follow the same regulation pattern (Frost et al. 2009). Endoplasmic reticulum stress and its downstream adaptive response, the unfolded protein response, have been proposed as another HIF$1 \alpha$-independent mechanism by which Redd- 1 can be up-regulated (Whitney et al. 2009). To test this hypothesis, we measured ATF4 and the active (spliced) form of XBP1 at the mRNA level, and we found a higher expression of both genes after exposure to hypoxia, indeed. The unfolded protein response could also have contributed to the increase in VEGF-A mRNA, usually attributed to HIF- $1 \alpha$, that we observed at the end of the hypoxic trial. IRE1 $\alpha$ and XBP1s have previously been reported to induce VEGF-A mRNA expression (Drogat et al. 2007). Altogether, our data show that PKB and S6K1 phosphorylation remained higher in hypoxia potentially due to higher plasma insulin concentrations and despite an increase in Redd-1 mRNA, a well-known inhibitor of the $\mathrm{PKB} / \mathrm{mTOR}$ pathway. However, it is highly probable that other untested factors also contributed to the regulation of $\mathrm{PKB}$ and $\mathrm{S} 6 \mathrm{~K} 1$.

\section{Environmental hypoxia affects protein breakdown to a minor extent}

As mentioned above, protein breakdown has often been understudied in studies dealing with hypoxia. Two studies performed on animal models have directly investigated the effect of hypoxia on the different proteolytic pathways. Favier et al. did not find any effect of chronic hypoxia (3 weeks, $6300 \mathrm{~m}$ ) on any component of the proteasomal, lysosomal and calcium-dependent systems in rat skeletal muscle (Favier et al. 2010). On the contrary, Chaudhary et al. reported that chronic hypoxia (2 weeks, $7620 \mathrm{~m}$ ) induced muscle atrophy and that the proteasomal and calpain systems were activated at the same time (Chaudhary et al. 2012). Based on those 2 studies, a clear-cut conclusion is thus difficult to draw. Both used very similar methodologies except the strain (Wistar (Favier et al. 2010) vs. Sprague-Dawley males (Chaudhary et al. 2012)), the altitude and the age of the animals. The latter issue could explain why Chaudhary, using young rats, found an increase in protein breakdown after exposure to hypoxia as protein turnover is known to be higher in younger rats than in adult rats. Growing rats are thus more sensitive to factors affecting protein synthesis and/or protein breakdown. Moreover, in the study of Chaudhary, the altitude was $1000 \mathrm{~m}$ higher than that in the study of Favier, which has probably favoured the catabolic 
state of the animals. In the present study, we did not find any change in either proteasome, or cathepsin, or calpain activities in adult subjects. This is the first time that protease activities are measured in skeletal muscle of subjects exposed to hypoxia. Based on our results, hypoxia seems to affect markers of protein synthesis to a larger extent than those of protein breakdown. Interestingly, we found that independently of the hypoxic response, the activity of the three main proteolytic systems in skeletal muscle was higher a few hours after a light meal in normoxia. This higher activity could not be explained by a decreased phosphorylation of FoxO1/3a, a master regulator of protein breakdown, as contrary to what expected its phosphorylation increased throughout the normoxic trial. Although the activities of the proteasome, cathepsin and calpain systems were not modified, we hypothesized that short-term hypoxia could have altered some key regulators of these pathways. This would prepare the different machineries to become more activated in case of prolonged exposition to hypoxia. Several well-known markers of the ubiquitin -proteasome pathway (MuRF-1 and MAFbx mRNA) (Bodine et al. 2001), the autophagy-lysosome (Bnip3 mRNA) (Tracy et al. 2007) and the ER stress-associated degradation systems (CHOP mRNA and protein) (Oyadomari \& Mori 2004) were quantified. Only MuRF-1 and MAFbx mRNA were modified after 4-h hypoxia and these changes occurred in an opposite way, MuRF-1 level being up-regulated and MAFbx down-regulated. Those 2 muscle-specific ligases have originally been thought to play a pivotal role in the regulation of the ubiquitin-proteasome pathway (Bodine et al. 2001). Since then, their role has been revised somewhat downwards, and it is not uncommon to see a specific regulation of each factor (Greenhaff et al. 2008, Jamart et al. 2012). We could have expected that the higher insulin concentration induced by hypoxia would have affected protein breakdown to a larger extent as insulin is known to affect protein breakdown rather than protein synthesis in skeletal muscle (Greenhaff et al. 2008). However, it was not the case in the present study. It is possible that exposure to hypoxia modulates the response of protein breakdown to insulin usually observed in normoxia, but this needs further investigation.

\section{Acute environmental hypoxia does not activate HIF-I $\alpha$ in skeletal muscle}

Acute exposure to $11 \% \mathrm{O}_{2}$ resulted in a large decrease in $\mathrm{SpO}_{2}$ in all subjects. Interestingly, individual $\mathrm{SpO}_{2}$ drops ranged from 12 to $36 \%$, indicating a high variability in hypoxic adaptation between subjects. Irrespective of the large decrease in $\mathrm{SpO}_{2}$, TOI only decreased by approx. $6 \%$ in hypoxia, which is in line with previous studies (Martin et al. 2009). Even though oxygen supply to skeletal muscle is drastically reduced, muscle oxygenation seems to stay rather stable under severe environmental hypoxia, probably because of the low muscle oxygen consumption at rest and the high affinity of myoglobin for oxygen (Ordway \& Garry 2004). It is noteworthy that, during exercise, TOI decreases much more severely than the $6 \%$ presented here not only in hypoxia but in normoxia as well (Martin et al. 2009, Masschelein et al. 2012). This large decrease in tissue oxygenation induced by exercise is accompanied by an up-regulation of HIF-1 $\alpha$ (Ameln et al. 2005), whereas in our resting conditions, we did not measure any change of the latter whether at the protein or at the mRNA level. All the observations we made in the present study are thus independent of HIF$1 \alpha$, which is not surprising as muscle oxygenation was barely affected. The latter suggests that other factors, that could be systemic, are involved in the activation of intramuscular signalling. Two likely candidates are insulin and cortisol, previously shown to be altered during hypoxic exposure (Larsen et al. 1997). Whereas plasma cortisol concentration was not modified by hypoxia, insulin returned more slowly to basal after a standardized breakfast in the hypoxic trial. Insulin concentration was twofold higher at the end of the exposure to environmental hypoxia and could partially explain several observations we made at this time, that is, higher phosphorylation of PKB and S6K1. The higher insulin concentration in the group exposed to hypoxia was not due to higher blood glucose concentrations. Glucose is a well-known stimulator of insulin secretion, but the 4-h exposure to hypoxia did not increase glucose blood level compared with normoxia. On the contrary, hypoxia tended to reduce blood glucose levels. Although we could not measure plasma catecholamine concentrations due to a lack of sample, it is possible that adrenaline contributed to the increase in insulin as adrenaline increases at high altitude (Mazzeo et al. 1994), and it regulates insulin secretion by the pancreas (Lacey et al. 1993). It is also possible that adrenaline also directly altered protein metabolism as it has been shown to increase protein synthesis (Navegantes et al. 2004) and to repress proteolysis in rat skeletal muscle (Navegantes et al. 2000).

\section{Limitations of the present study}

The major limitation of this study is not having taken a biopsy before the breakfast. The lack of sample at this time point does not allow drawing any conclusion about the effect of breakfast itself. However, this was not the purpose of this study as the effect of feeding on protein synthesis and breakdown is already well 
known (Atherton \& Smith 2012). We also have to acknowledge that we did not directly measure protein synthesis and protein breakdown, but we quantified several markers of those processes. Finally, the physiological challenges experienced by the human body at high altitude are far more complex than those experienced with the normobaric model used in this study. Therefore, the results should be interpreted with caution when extrapolating to muscle protein synthesis and protein breakdown at high altitude.

\section{Conclusion}

In conclusion, contrary to our original hypothesis and despite an increase in the mRNA level of Redd1, an inhibitor of the mTOR pathway, short-term acute hypoxia induces a higher response of PKB and S6K1 $4 \mathrm{~h}$ after a meal that could at least partially been explained by an increase in plasma insulin concentration. Further investigation will be required to study the repeated response to a standardized meal during chronic hypoxia, which could differ from the one observed in this study. Long-term exposure to hypoxia could create a state of anabolic resistance that we did not observe on a short-term.

\section{Conflict of interest}

The authors do not have any conflicts of interest.

The authors would like to thank Monique Ramaekers for technical assistance, Katrien De Bock for providing cell culture samples and the volunteers who participated to this study. This work was supported by grants to $\mathrm{PH}$ from the 'Onderzoeksraad KU Leuven' (OT09/33) and from the FWO Vlaanderen (G.0706.09) and to MF from the 'Fonds de la Recherche Scientifique Médicale' (FRSM 3.4514.) and from the 'Fonds Spéciaux de Recherche Université catholique de Louvain'.

\section{References}

Ameln, H., Gustafsson, T., Sundberg, C.J., Okamoto, K., Jansson, E., Poellinger, L. \& Makino, Y. 2005. Physiological activation of hypoxia inducible factor-1 in human skeletal muscle. FASEB J 19, 1009-1011.

Arsham, A.M., Howell, J.J. \& Simon, M.C. 2003. A novel hypoxia-inducible factor-independent hypoxic response regulating mammalian target of rapamycin and its targets. J Biol Chem 278, 29655-29660.

Atherton, P.J. \& Smith, K. 2012. Muscle protein synthesis in response to nutrition and exercise. J Physiol 590, 1049-1057.

Baldi, S., Aquilani, R., Pinna, G.D., Poggi, P., De Martini, A. \& Bruschi, C. 2010. Fat-free mass change after nutritional rehabilitation in weight losing COPD: role of insulin, C-reactive protein and tissue hypoxia. Int $J$ Chron Obstruct Pulmon Dis 5, 29-39.
Bodine, S.C., Latres, E., Baumhueter, S., Lai, V.K., Nunez, L., Clarke, B.A., Poueymirou, W.T., Panaro, F.J., Na, E., Dharmarajan, K., Pan, Z.Q., Valenzuela, D.M., DeChiara, T.M., Stitt, T.N., Yancopoulos, G.D. \& Glass, D.J. 2001. Identification of ubiquitin ligases required for skeletal muscle atrophy. Science 294, 1704-1708.

Cam, H., Easton, J.B., High, A. \& Houghton, P.J. 2010. mTORC1 signaling under hypoxic conditions is controlled by ATM-dependent phosphorylation of HIF-1alpha. Mol Cell 40, 509-520.

Chaudhary, P., Suryakumar, G., Prasad, R., Singh, S.N., Ali, S. \& Ilavazhagan, G. 2012. Chronic hypobaric hypoxia mediated skeletal muscle atrophy: role of ubiquitin-proteasome pathway and calpains. Mol Cell Biochem 364, 101-113.

Deldicque, L., Cani, P.D., Philp, A., Raymackers, J.M., Meakin, P.J., Ashford, M.L., Delzenne, N.M., Francaux, M. \& Baar, K. 2010a. The unfolded protein response is activated in skeletal muscle by high-fat feeding: potential role in the downregulation of protein synthesis. Am J Physiol Endocrinol Metab 299, E695-E705.

Deldicque, L., De Bock, K., Maris, M., Ramaekers, M., Nielens, H., Francaux, M. \& Hespel, P. 2010b. Increased p70s6k phosphorylation during intake of a protein-carbohydrate drink following resistance exercise in the fasted state. Eur J Appl Physiol 108, 791-800.

DeYoung, M.P., Horak, P., Sofer, A., Sgroi, D. \& Ellisen, L.W. 2008. Hypoxia regulates TSC1/2-mTOR signaling and tumor suppression through REDD1-mediated 14-3-3 shuttling. Genes Dev 22, 239-251.

Drogat, B., Auguste, P., Nguyen, D.T., Bouchecareilh, M., Pineau, R., Nalbantoglu, J., Kaufman, R.J., Chevet, E., Bikfalvi, A. \& Moenner, M. 2007. IRE1 signaling is essential for ischemia-induced vascular endothelial growth factor-A expression and contributes to angiogenesis and tumor growth in vivo. Cancer Res 67, 6700-6707.

Etheridge, T., Atherton, P.J., Wilkinson, D., Selby, A., Rankin, D., Webborn, N., Smith, K. \& Watt, P.W. 2011. Effects of hypoxia on muscle protein synthesis and anabolic signaling at rest and in response to acute resistance exercise. Am J Physiol Endocrinol Metab 301, E697-E702.

Favier, F.B., Costes, F., Defour, A., Bonnefoy, R., Lefai, E., Bauge, S., Peinnequin, A., Benoit, H. \& Freyssenet, D. 2010. Downregulation of Akt/mammalian target of rapamycin pathway in skeletal muscle is associated with increased REDD1 expression in response to chronic hypoxia. Am J Physiol Regul Integr Comp Physiol 298, R1659-R1666.

Ferrari, M., Mottola, L. \& Quaresima, V. 2004. Principles, techniques, and limitations of near infrared spectroscopy. Can J Appl Physiol 29, 463-487.

Frost, R.A., Huber, D., Pruznak, A. \& Lang, C.H. 2009. Regulation of REDD1 by insulin-like growth factor-I in skeletal muscle and myotubes. J Cell Biochem 108, 1192-1202.

Garvey, J.F., Taylor, C.T. \& McNicholas, W.T. 2009. Cardiovascular disease in obstructive sleep apnoea syndrome: the role of intermittent hypoxia and inflammation. Eur Respir J 33, 1195-1205.

Gingras, A.C., Gygi, S.P., Raught, B., Polakiewicz, R.D., Abraham, R.T., Hoekstra, M.F., Aebersold, R. \& Sonen- 
berg, N. 1999. Regulation of 4E-BP1 phosphorylation: a novel two-step mechanism. Genes Dev 13, 1422-1437.

Gingras, A.C., Raught, B., Gygi, S.P., Niedzwiecka, A., Miron, M., Burley, S.K., Polakiewicz, R.D., WyslouchCieszynska, A., Aebersold, R. \& Sonenberg, N. 2001. Hierarchical phosphorylation of the translation inhibitor 4E-BP1. Genes Dev 15, 2852-2864.

Greenhaff, P.L., Karagounis, L.G., Peirce, N., Simpson, E.J., Hazell, M., Layfield, R., Wackerhage, H., Smith, K., Atherton, P., Selby, A. \& Rennie, M.J. 2008. Disassociation between the effects of amino acids and insulin on signaling, ubiquitin ligases, and protein turnover in human muscle. Am J Physiol Endocrinol Metab 295, E595-E604.

Greer, S.N., Metcalf, J.L., Wang, Y. \& Ohh, M. 2012. The updated biology of hypoxia-inducible factor. ЕMBO J 31, $2448-2460$.

Grocott, M., Montgomery, H. \& Vercueil, A. 2007. Highaltitude physiology and pathophysiology: implications and relevance for intensive care medicine. Crit Care 11, 203.

Hoppeler, H., Kleinert, E., Schlegel, C., Claassen, H., Howald, H., Kayar, S.R. \& Cerretelli, P. 1990. Morphological adaptations of human skeletal muscle to chronic hypoxia. Int J Sports Med 11(Suppl 1), S3-S9.

Jackman, R.W. \& Kandarian, S.C. 2004. The molecular basis of skeletal muscle atrophy. Am J Physiol Cell Physiol 287, C834-C843.

Jamart, C., Francaux, M., Millet, G.Y., Deldicque, L., Frere, D. \& Feasson, L. 2012. Modulation of autophagy and ubiquitin-proteasome pathways during ultra-endurance running. J Appl Physiol 112, 1529-1537.

Jamart, C., Raymackers, J.M., Li, A.G., Deldicque, L. \& Francaux, M. 2011. Prevention of muscle disuse atrophy by MG132 proteasome inhibitor. Muscle Nerve 43, 708-716.

Koritzinsky, M., Magagnin, M.G., van den Beucken, T., Seigneuric, R., Savelkouls, K., Dostie, J., Pyronnet, S., Kaufman, R.J., Weppler, S.A., Voncken, J.W., Lambin, P., Koumenis, C., Sonenberg, N. \& Wouters, B.G. 2006. Gene expression during acute and prolonged hypoxia is regulated by distinct mechanisms of translational control. EMBO J 25, 1114-1125.

Koumenis, C., Naczki, C., Koritzinsky, M., Rastani, S., Diehl, A., Sonenberg, N., Koromilas, A. \& Wouters, B.G. 2002. Regulation of protein synthesis by hypoxia via activation of the endoplasmic reticulum kinase PERK and phosphorylation of the translation initiation factor eIF2alpha. Mol Cell Biol 22, 7405-7416.

Koumenis, C. \& Wouters, B.G. 2006. “Translating” tumor hypoxia: unfolded protein response (UPR)-dependent and UPR-independent pathways. Mol Cancer Res 4, 423-436.

Lacey, R.J., Cable, H.C., James, R.F., London, N.J., Scarpello, J.H. \& Morgan, N.G. 1993. Concentration-dependent effects of adrenaline on the profile of insulin secretion from isolated human islets of Langerhans. J Endocrinol 138, 555-563.

Laplante, M. \& Sabatini, D.M. 2012. mTOR signaling in growth control and disease. Cell 149, 274-293.

Larsen, J.J., Hansen, J.M., Olsen, N.V., Galbo, H. \& Dela, F. 1997. The effect of altitude hypoxia on glucose homeostasis in men. J Physiol 504(Pt 1), 241-249.
Lee, W.H., Kim, Y.W., Choi, J.H., Brooks, S.C. III, Lee, M.O. \& Kim, S.G. 2009. Oltipraz and dithiolethione congeners inhibit hypoxia-inducible factor-1alpha activity through p70 ribosomal S6 kinase-1 inhibition and $\mathrm{H} 2 \mathrm{O} 2$ scavenging effect. Mol Cancer Ther 8, 2791-2802.

Liu, L., Cash, T.P., Jones, R.G., Keith, B., Thompson, C.B. \& Simon, M.C. 2006. Hypoxia-induced energy stress regulates mRNA translation and cell growth. Mol Cell 21, 521-531.

Lundby, C., Pilegaard, H., Andersen, J.L., van Hall, G., Sander, M. \& Calbet, J.A. 2004. Acclimatization to $4100 \mathrm{~m}$ does not change capillary density or mRNA expression of potential angiogenesis regulatory factors in human skeletal muscle. J Exp Biol 207, 3865-3871.

MacDougall, J.D., Green, H.J., Sutton, J.R., Coates, G., Cymerman, A., Young, P. \& Houston, C.S. 1991. Operation Everest II: structural adaptations in skeletal muscle in response to extreme simulated altitude. Acta Physiol Scand $142,421-427$.

Martin, D.S., Levett, D.Z., Mythen, M. \& Grocott, M.P. 2009. Changes in skeletal muscle oxygenation during exercise measured by near-infrared spectroscopy on ascent to altitude. Crit Care 13(Suppl 5), S7.

Masschelein, E., Van Thienen, R., Wang, X., Van Schepdael, A., Thomis, M. \& Hespel, P. 2012. Dietary nitrate improves muscle but not cerebral oxygenation status during exercise in hypoxia. J Appl Physiol 113, 736-745.

Mazzeo, R.S., Wolfel, E.E., Butterfield, G.E. \& Reeves, J.T. 1994. Sympathetic response during 21 days at high altitude $(4,300 \mathrm{~m})$ as determined by urinary and arterial catecholamines. Metabolism 43, 1226-1232.

McGee, S.L. \& Hargreaves, M. 2010. AMPK-mediated regulation of transcription in skeletal muscle. Clin Sci (Lond) 118, 507-518.

Mizuno, M., Savard, G.K., Areskog, N.H., Lundby, C. \& Saltin, B. 2008. Skeletal muscle adaptations to prolonged exposure to extreme altitude: a role of physical activity? High Alt Med Biol 9, 311-317.

Navegantes, L.C., Resano, N.M., Baviera, A.M., Migliorini, R.H. \& Kettelhut, I.C. 2004. Effect of sympathetic denervation on the rate of protein synthesis in rat skeletal muscle. Am J Physiol Endocrinol Metab 286, E642-E647.

Navegantes, L.C., Resano, N.M., Migliorini, R.H. \& Kettelhut, I.C. 2000. Role of adrenoceptors and cAMP on the catecholamine-induced inhibition of proteolysis in rat skeletal muscle. Am J Physiol Endocrinol Metab 279, E663E668.

Ordway, G.A. \& Garry, D.J. 2004. Myoglobin: an essential hemoprotein in striated muscle. J Exp Biol 207, 3441-3446.

Oyadomari, S. \& Mori, M. 2004. Roles of CHOP/ GADD153 in endoplasmic reticulum stress. Cell Death Differ 11, 381-389.

Ron, D. \& Walter, P. 2007. Signal integration in the endoplasmic reticulum unfolded protein response. Nat Rev Mol Cell Biol 8, 519-529.

Schols, A.M., Broekhuizen, R., Weling-Scheepers, C.A. \& Wouters, E.F. 2005. Body composition and mortality in chronic obstructive pulmonary disease. Am J Clin Nutr 82, $53-59$. 
Schwarzer, R., Tondera, D., Arnold, W., Giese, K., Klippel, A. \& Kaufmann, J. 2005. REDD1 integrates hypoxia-mediated survival signaling downstream of phosphatidylinositol 3-kinase. Oncogene 24, 1138-1149.

Shoshani, T., Faerman, A., Mett, I., Zelin, E., Tenne, T., Gorodin, S., Moshel, Y., Elbaz, S., Budanov, A., Chajut, A., Kalinski, H., Kamer, I., Rozen, A., Mor, O., Keshet, E., Leshkowitz, D., et al. 2002. Identification of a novel hypoxia-inducible factor 1-responsive gene, RTP801, involved in apoptosis. Mol Cell Biol 22, 2283-2293.

Stitt, T.N., Drujan, D., Clarke, B.A., Panaro, F., Timofeyva, Y., Kline, W.O., Gonzalez, M., Yancopoulos, G.D. \& Glass, D.J. 2004. The IGF-1/PI3K/Akt pathway prevents expression of muscle atrophy-induced ubiquitin ligases by inhibiting FOXO transcription factors. Mol Cell 14, 395403.

Tagliavacca, L., Caretti, A., Bianciardi, P. \& Samaja, M. 2012. In vivo up-regulation of the unfolded protein response after hypoxia. Biochim Biophys Acta 1820, 900-906.

Tracy, K., Dibling, B.C., Spike, B.T., Knabb, J.R., Schumacker, P. \& Macleod, K.F. 2007. BNIP3 is an RB/E2F target gene required for hypoxia-induced autophagy. Mol Cell Biol 27, 6229-6242.
Vandesompele, J., De Preter, K., Pattyn, F., Poppe, B., Van Roy, N., De Paepe, A. \& Speleman, F. 2002. Accurate normalization of real-time quantitative RT-PCR data by geometric averaging of multiple internal control genes. Genome Biol 3, RESEARCH0034.

Vigano, A., Ripamonti, M., De Palma, S., Capitanio, D., Vasso, M., Wait, R., Lundby, C., Cerretelli, P. \& Gelfi, C. 2008. Proteins modulation in human skeletal muscle in the early phase of adaptation to hypobaric hypoxia. Proteomics 8, 4668-4679.

Vincent, B., Windelinckx, A., Nielens, H., Ramaekers, M., Van Leemputte, M., Hespel, P. \& Thomis, M.A. 2010. Protective role of alpha-actinin-3 in the response to an acute eccentric exercise bout. J Appl Physiol 109, 564-573.

Whitney, M.L., Jefferson, L.S. \& Kimball, S.R. 2009. ATF4 is necessary and sufficient for ER stress-induced upregulation of REDD1 expression. Biochem Biophys Res Commun 379, 451-455.

Wouters, B.G. \& Koritzinsky, M. 2008. Hypoxia signalling through $\mathrm{mTOR}$ and the unfolded protein response in cancer. Nat Rev Cancer 8, 851-864.

Wust, R.C. \& Degens, H. 2007. Factors contributing to muscle wasting and dysfunction in COPD patients. Int J Chron Obstruct Pulmon Dis 2, 289-300. 